\title{
Photodegradation of roxarsone in the aquatic environment: influencing factors, mechanisms and artificial neural network modeling
}

\section{Jizhong Meng}

Hefei University of Technology

\section{Arong Arong}

Hefei University of Technology

\section{Shoujun Yuan}

Hefei University of Technology

\section{Wei Wang}

Hefei University of Technology

Juliang Jin

Hefei University of Technology

Xinmin Zhan

National University of Ireland Galway

\section{Liwen Xiao}

Trinity College Dublin: The University of Dublin Trinity College

Zhenhu Hu ( $\nabla$ zhhu@hfut.edu.cn )

Hefei University of Technology https://orcid.org/0000-0002-4873-1174

\section{Research Article}

Keywords: Roxarsone, photodegradation, mechanism, artificial neural network, modeling

Posted Date: May 7th, 2021

DOI: https://doi.org/10.21203/rs.3.rs-452155/v1

License: (c) (1) This work is licensed under a Creative Commons Attribution 4.0 International License. Read Full License

Version of Record: A version of this preprint was published at Environmental Science and Pollution Research on September 4th, 2021. See the published version at https://doi.org/10.1007/s11356-02116183-5. 


\section{Abstract}

Roxarsone (ROX) is an organoarsenic feed additive, and can be discharged into aquatic environment. ROX can photodegrade into more toxic inorganic arsenics, causing arsenic pollution. However, the photodegradation behavior of ROX in aquatic environment is still unclear. To better understand ROX photodegradation behavior, this study investigated the ROX photodegradation mechanism and influencing factors, and modeled the photodegradation process. The results showed that ROX in the aquatic environment was degraded to inorganic $\mathrm{As}(\mathrm{III})$ and $\mathrm{As}(\mathrm{V})$ under light irradiation. The degradation efficiency was enhanced by $25 \%$ with the increase of light intensity from $300 \mu \mathrm{W} / \mathrm{cm}^{2}$ to $800 \mu \mathrm{W} / \mathrm{cm}^{2}$ via indirect photolysis. The photodegradation was temperature dependence, but was only slightly affected by $\mathrm{pH}$. Nitrate ion $\left(\mathrm{NO}_{3}{ }^{-}\right)$had an obvious influence, but sulfate, carbonate, and chlorate ions had a negligible effect on ROX degradation. Dissolved organic matter (DOM) in the solution inhibited the photodegradation. ROX photodegradation was mainly mediated by reactive oxygen species (in the form of single oxygen ${ }^{1} \mathrm{O}_{2}$ ) generated through ROX self-sensitization under irradiation. Based on the data of factors affecting ROX photodegradation, ROX photodegradation model was built and trained by an artificial neural network (ANN), and the predicted degradation rate was in good agreement with the real values with a root mean square error of 1.008 . This study improved the understanding of ROX photodegradation behavior and provided a basis for controlling the pollution from ROX photodegradation.

\section{Introduction}

Roxarsone (ROX, 4-hydroxy-3-nitrophenylarsonic acid) is an organoarsenical and widely used in the poultry industry as a feed additive to improve feed efficiency, prevent coccidial intestinal parasites and increase growth with the dosage of $20-50 \mathrm{mg} / \mathrm{kg}$ (Bednar et al., 2003; Shui et al., 2016; Zhao et al., 2020). Most of ROX in the feed is excreted to poultry litter. It has been reported that $29.8 \mathrm{mg} / \mathrm{kg}$ of total arsenic concentration was detected in the poultry litter (Fisher et al., 2015; Zhao et al., 2020). Because ROX is water-soluble, the land application of poultry litter can result in the transformation of ROX into receiving waters after rain events (Cortinas et al., 2006; Liu et al., 2015; Yang et al., 2016). In the aquatic environment, ROX is degraded into inorganic arsenics (arsenite (As(III) and arsenate (As(V)), which are more toxic and mobile than ROX (Chen et al., 2019; Lei et al., 2019; Mangalgiri et al., 2015; Nguyen et al., 2019; Rutherford et al., 2003; Su et al., 2019; Tang et al., 2019; Wang et al., 2021; Zheng et al., 2014), and part of inorganic arsenics is converted into volatile arsenics (Tang et al., 2020; Tang et al., 2019).

Therefore, the understanding and prediction of ROX degradation behavior in the aquatic environment are very important for controlling the pollution caused by ROX.

ROX could be photodegraded in the aquatic environment, such as in poultry litter leachates and surface water (Chen et al., 2020; Mangalgiri et al., 2015), but ROX photodegradation behavior has not been fully understood. In general, the photodegradation of organic contaminants can be divided into two main types: direct photolysis and indirect photolysis. Organic contaminants can be directly photodegraded 
through the absorbance of photons and/or indirectly photodegraded by reactive oxygen species (ROS) (. $\mathrm{OH}$ or single oxygen $\left({ }^{1} \mathrm{O}_{2}\right)$ ) and other kinds of reactive radicals (Huang et al., 2020; Sharpless, 2012). The ROX photodegradation process has not been clearly investigated. Also, photodegradation is affected by water quality and environmental conditions (Diepens and Gijsman, 2009). Light intensity and temperature promoted photodegradation efficiency, while dissolved organic matter (DOM) enhanced or inhibited the photodegradation of organic contaminants (Diepens and Gijsman, 2009; Hansen et al., 2016). Therefore, investigating the factors affecting ROX photodegradation would improve the understanding of ROX photodegradation behavior.

Modeling the ROX photodegradation process will be helpful for predicting the photodegradation of ROX in the aquatic environment. Artificial neural networks (ANNs) are widely used in building the complex relationship between input and output data (Elsheikh et al., 2019). In addition, ANNs have the learning and adapting ability to update the system's selves(Cabaneros et al., 2019). Therefore, ANNs are introduced to model many complex processes without a theoretical foundation. Here, ANNs are used to model the ROX photodegradation process.

The purpose of this study was to investigate: (1) the factors affecting ROX photodegradation, (2) the mechanisms of ROX photodegradation, and (3) based on the data of the factors affecting ROX photodegradation, building an ANNs model for predicting ROX photodegradation. This study will improve the understanding and prediction of ROX photodegradation in the aquatic environment.

\section{Materials And Methods \\ 2.1 Materials}

Roxarsone (4-hydroxy-3-nitrophenylarsonic acid, $\mathrm{C}_{6} \mathrm{H}_{6} \mathrm{AsNO}_{6}$, purity > 99\%) was purchased from Sigma Chem. Co. Humic acid $\left(\mathrm{C}_{9} \mathrm{H}_{9} \mathrm{NO}_{6}\right.$, purity $\left.>90 \%\right)$, fulvic acid $\left(\mathrm{C}_{14} \mathrm{H}_{12} \mathrm{O}_{8}\right.$, purity $\left.>85 \%\right)$ and deuterium oxide $\left(D_{2} \mathrm{O}\right.$, purity $\left.>99.9 \%\right)$ were purchased from Macklin Chem. Co. Other chemicals were purchased from Sinopharm Chemical Reagent Co., Ltd. The aquatic humic substances were used to simulate DOM, and the aquatic humic substances were prepared using equal amounts of humic acid and fulvic acid (Uwayezu et al., 2019). All solutions were prepared using ultrapure water.

Surface water was collected from the Hubing pond on the campus. Wastewater was collected from a local poultry farm in Hefei and diluted 5 times for use. Both waters were filtered through $0.45 \mu \mathrm{m}$ of the cellulosic membrane and sterilized prior to use. The $\mathrm{pH}$ of surface water was $6.5 \pm 0.2, \mathrm{NO}_{3}{ }^{-}$ concentration was below $0.8 \mathrm{mg} / \mathrm{L}$, the detection limit, and DOM was $23.0 \mathrm{mg} / \mathrm{L}$. The $\mathrm{pH}$ of the wastewater was $6.5 \pm 0.2, \mathrm{NO}_{3}{ }^{-}$concentration was $10.0 \pm 0.2 \mathrm{mg} / \mathrm{L}$, and DOM was $98.0 \mathrm{mg} / \mathrm{L}$, respectively. The DOM concentration refers to the DOC concentration.

\subsection{Experimental setup}


This study was composed of three parts. In the first part, the influence of environmental factors such as light intensity, temperature, $\mathrm{pH}$, common anions, DOM and ROX concentration on ROX photodegradation was investigated. In the second part, the mechanisms of ROX photodegradation were explored. In the third part, the modeling of ROX photodegradation was built based on ANNs. The experiment was conducted in the laboratory with $50 \mathrm{~mL}$ glass beakers, and a xenon arc lamp (500W, 220-1200 nm) was placed on the top of the beakers to simulate sunlight irradiation.

In the investigation of influential factors, the general photodegradation conditions were set at light intensity $800 \pm 30 \mu \mathrm{W} / \mathrm{cm}^{2}$ (measured at $254 \mathrm{~nm}$ ), ROX concentration $10.0 \pm 0.2 \mu \mathrm{M}$, temperature $25.0 \pm$ $2{ }^{\circ} \mathrm{C}$, and $\mathrm{pH} 7.0 \pm 0.2$. While as the varied factors, light intensity from $0 \mu \mathrm{W} / \mathrm{cm}^{2}$ to $1200 \mu \mathrm{W} / \mathrm{cm}^{2}$, temperature from $10.0^{\circ} \mathrm{C}$ to $40.0^{\circ} \mathrm{C}, \mathrm{pH}$ from 3.0 to 11.0 , and ROX concentration from $1.0 \mu \mathrm{M}$ to 1000.0 $\mu \mathrm{M}$ were investigated. The influence of common anions of nitrate, sulfate, carbonate and chlorate were investigated at a concentration of $10.0 \mathrm{mg} / \mathrm{L}$, and the identified anions affecting ROX degradation were further investigated with concentration ranging from 1.0 to $100.0 \mathrm{mg} / \mathrm{L}$. DOM affecting ROX degradation was also investigated at concentrations ranged from 1.0 to $100.0 \mathrm{mg} / \mathrm{L}$.

In the investigation of the mechanisms of ROX photodegradation, the role of dissolved oxygen (DO) on photodegradation was identified. In which, the reaction beaker was purged with $\mathrm{O}_{2}$ or $\mathrm{N}_{2}$, and sealed immediately after purging for subsequent irradiation. The main species of reactive oxygen were further validated by the difference of ROX degradation rate between in $20 \mathrm{~mL} \mathrm{H}_{2} \mathrm{O}$ and $\mathrm{D}_{2} \mathrm{O}$ solution because the half-life period of ${ }^{1} \mathrm{O}_{2}$ in $\mathrm{D}_{2} \mathrm{O}$ is much longer than that in $\mathrm{H}_{2} \mathrm{O}\left(\mathrm{k}_{\mathrm{s}}: 1.8 \times 10^{4} \mathrm{~S}^{-1}\right.$ vs $\left.2.5 \times 10^{5} \mathrm{~S}^{-1}\right)$ (Latch et al., 2003).

For predicting the ROX photodegradation under different conditions, the model of ROX photodegradation was built using Matlab with a three-layer backpropagation algorithm ANN. In this ANN, a tangent sigmoid transfer function (tansig) between input layer and hidden layer, a linear transfer function (purelin) between hidden layer and output layer and a Levenberg-Marquardt backpropagation algorithm were applied (Ye et al., 2016). The backpropagation algorithm with forward pass procedure was utilized as shown in Fig. 1, and the formulas were shown in Eq. 1.

\section{See equation 1 in the supplementary files.}

In detail, inputs were weighted by the connections $\left(w^{(1)}\right)$ and added bias $\left(b_{j}\right)$ between the input and hidden layer, then the results were weighted by the connections $\left(w^{(2)}\right)$ and added bias $\left(b_{i}\right)$ between the input and hidden layer. The weights and bias values were adjusted automatically by the error between output data and true data (Amani-Ghadim and Dorraji, 2015). The model was trained using the experimental data obtained in the investigation of influencing factors. In the training process, the parameter of maximum epochs number was 500 , the error goal was 0.001 , and other training parameters were used as the defaults in ANN-tool. The details of training were described in the results and discussion section. 
For validating the prediction accuracy of ROX degradation with the built ANN model, the ROX photodegradation in ultrapure water, surface water and wastewater was investigated under natural sunlight irradiation from 9:00 am to 5:00 pm with continuous 10 days (in August). The experimental condition was set as input data in the ANN model, and the predicted degradation efficiencies using the ANN model was compared with the real degradation efficiencies to validate the accuracy of the model prediction. During the ROX photodegradation under natural sunlight irradiation, the ambient temperature varied from $28^{\circ} \mathrm{C}$ to $40^{\circ} \mathrm{C}$, and the temperature in input data was set as $35^{\circ} \mathrm{C}$. The sunlight intensity ranged from $1100 \mu \mathrm{W} / \mathrm{cm}^{2}$ to $1400 \mu \mathrm{W} / \mathrm{cm}^{2}$, and the sunlight intensity in input data was set as 1200 $\mu \mathrm{W} / \mathrm{cm}^{2}$.

\subsection{Analytical methods}

ROX concentration was determined by high performance liquid chromatography (HPLC-1260 Infinity, Agilent Technology Ltd., USA) equipped with a C18 column $(4.6 \times 250 \mathrm{~mm}, 5 \mu \mathrm{m})$ and a diode array UVvis detector at $264 \mathrm{~nm}$ wavelength. The mobile phase was composed of $10.0 \mathrm{mM}$ ammonium acetate, methanol and acetic acid (85:15:0.1, V/V/V) at a flow rate of $1.0 \mathrm{~mL} / \mathrm{min}$ (Zhang et al., 2014).

Arsenic species were analyzed using high performance liquid chromatography - hydride generation atomic fluorescence spectrometry (HPLC-HG- AFS). The arsenic species were firstly separated with a 250 $\times 4.1 \mathrm{~mm}$ anion-exchange column (PRP X-100, Hamilton, Switzerland) at $30.0^{\circ} \mathrm{C}$, and then reduced to arsenic hydride by the mixed solution of $20.00 \mathrm{~g} / \mathrm{L} \mathrm{KBH}_{4}$ and $5.00 \mathrm{~g} / \mathrm{L} \mathrm{KOH}$ for detection (Tang et al., 2017). The mobile phase was $10 \mathrm{mM}\left(\mathrm{NH}_{4}\right)_{2} \mathrm{HPO}_{4}$ solution (adjusted to $\mathrm{pH} 6.0$ using $10 \%$ formic acid) at a flow rate of $1.0 \mathrm{~mL} / \mathrm{min}$.

\section{Results And Discussion}

\subsection{ROX photodegradation behavior}

\subsubsection{Feasibility of ROX photodegradation}

ROX photodegradation in ultrapure water was investigated under a light intensity of $800 \pm 30 \mu \mathrm{W} / \mathrm{cm}^{2}$. As shown in Fig. 2, about 38 \% ROX was degraded after 40 hours irradiation. Inorganic arsenics were generated accompanying with ROX photodegradation. The As(V) concentration was gradually increased to $2.9 \mu \mathrm{M}$, which was higher than that of $\mathrm{As}(\mathrm{III})(0.9 \mu \mathrm{M})$. It was reported that $\mathrm{As}$ (III) was generated from ROX degradation and further oxidized to As(V) (Meng et al., 2019; Xie et al., 2016). Those results indicated that ROX in the aquatic environment was oxidized to inorganic arsenics under light irradiation. Inorganic arsenics are more toxic than their parent compound. Therefore, investigating the influencing factors and ROX photodegradation mechanisms would improve the understanding of the ROX photodegradation behavior in the aquatic environment. 


\subsubsection{Factors affecting ROX photodegradation}

ROX photodegradation is a complex process and affected by many factors. In this study, the influence of light intensity, temperature, $\mathrm{pH}$, ions concentration, DOM concentration and ROX concentration on the photodegradation process were investigated.

For assessing the effect of light intensity on ROX photodegradation, four gradients light intensity (300, 500,800 and $1200 \mu \mathrm{W} / \mathrm{cm}^{2}$ ) were investigated in ROX degradation process. As shown in Fig. 3a, the degradation rate gradually increased with the increase of light intensity, and the degradation efficiency was enhanced by $25 \%$ with the light intensity increased from $300 \mu \mathrm{W} / \mathrm{cm}^{2}$ to $800 \mu \mathrm{W} / \mathrm{cm}^{2}$, indicating that the light intensity was an important factor affecting ROX photodegradation. If the ROX was photodegraded via direct photolysis, the photolysis rate constant would depend on the sunlight intensity (Niu et al., 2013). According to Fig. 3a, when light intensity was higher than $800 \mu \mathrm{W} / \mathrm{cm}^{2}$, ROX degradation rate was not affected by the increase of light intensity. Therefore, the degradation might be due to indirect photolysis during the photodegradation.

The temperature was one of the most important parameters affecting the photodegradation process. The photodegradation of ROX at different temperatures $\left(10.0,25.0\right.$, and $40.0^{\circ} \mathrm{C}$ ) was investigated. As shown in Fig. $3 \mathrm{~b}$, about $41 \%, 46 \%$ and $53 \%$ ROX were degraded after 40 hours irradiation at $10.0^{\circ} \mathrm{C}, 25.0^{\circ} \mathrm{C}$ and $40.0^{\circ} \mathrm{C}$, respectively. As compared to $10.0^{\circ} \mathrm{C}$, the degradation efficiency was enhanced by $12 \%$ at $40.0^{\circ} \mathrm{C}$, indicating that the photodegradation was temperature dependence and high temperature promoted the photodegradation rate. $\mathrm{pH}$ is also an important factor affecting the photodegradation of organic matter. As shown in Fig. 3c, ROX photodegradation was slightly affected by $\mathrm{pH}$, and higher $\mathrm{pH}$ resulted in an increasing ROX degradation rate, which might be caused by deprotonating the phenolic group of ROX $(\mathrm{pKa}=5.8)$.

Anions in the aquatic environment might affect the ROX photodegradation. The effect of common anions on ROX photodegradation was carried out in ultrapure water. The results revealed that sulfate, carbonate, and chlorate ions had a negligible effect but nitrate ion $\left(\mathrm{NO}_{3}{ }^{-}\right)$had an obvious influence on ROX degradation (shown in Fig. S1). Hence, the effect of $\mathrm{NO}_{3}{ }^{-}$was further investigated. As shown in Fig. 3d, the ROX photodegradation rate increased with the increase of $\mathrm{NO}_{3}{ }^{-}$concentration, and degradation efficiency was promoted by $6 \%, 17 \%$, and $47 \%$ with $1.0 \mathrm{mg} / \mathrm{L}, 10.0 \mathrm{mg} / \mathrm{L}$, and $100.0 \mathrm{mg} / \mathrm{L} \mathrm{of} \mathrm{NO}_{3}{ }^{-}$, respectively. $\mathrm{NO}_{3}{ }^{-}$in aqueous environment can absorb photons in the UV range $(\lambda<350 \mathrm{~nm})$ and produce reactive species $\left(\mathrm{O}_{2}\right.$-- and $\left.\cdot \mathrm{OH}\right)$ (Wang et al., 2017), which have a high oxidizing capacity and can oxidize organic compounds rapidly.

DOM is widely existed in the natural aquatic environment and affects the photodegradation rate in aquatic environment with enhancement or inhibition (Qin-Tao and Williams, 2007). It has reported that DOM can enhance the photodegradation rate because of the generation of oxidizing species $\left(\mathrm{O}_{2} \cdot\right.$ and $\left.\cdot \mathrm{OH}\right)$ or secondary reactive species ( ${ }^{3}$ DOM) (Janssen et al., 2014), or decrease the photodegradation rate 
because of light screening or ROSs scavenging (Canonica and Laubscher, 2008; Wenk et al., 2013; Xu et al., 2009). As shown in Fig. 3e, ROX degradation rate was decreased with increasing DOM concentration from $35 \%$ of $1.0 \mathrm{mg} / \mathrm{L} \mathrm{DOM}$ to $11 \%$ of $100.0 \mathrm{mg} / \mathrm{L} \mathrm{DOM}$, indicating that DOM inhibited ROX photodegradation. Also, ROX degradation was affected by the initial ROX concentration. As shown in Fig. $3 f$, the ROX photodegradation percentage decreased with the increase of ROX concentration.

\subsubsection{Mechanisms of ROX photodegradation}

The mechanisms of ROX photodegradation were further investigated. According to the above results, indirect photolysis might be one of the main mechanisms for ROX photodegradation. The direct and indirect photolysis was identified by the generated oxidizing species involved in the degradation process (Wang et al., 2017). Generally, ROS is the main oxidizing species in indirect photolysis (Xu et al., 2008). Hence, the role of ROS in ROX degradation was investigated with $\mathrm{O}_{2}$ purging and $\mathrm{N}_{2}$ purging, because DO can increase the concentration of ROS. The DO of the solution before purging was $7.5 \pm 0.2 \mathrm{mg} / \mathrm{L}$, and the corresponding values were $12.0 \pm 0.2 \mathrm{mg} / \mathrm{L}$ and $1.2 \pm 0.1 \mathrm{mg} / \mathrm{L}$ after $\mathrm{O}_{2}$ and $\mathrm{N}_{2}$ purging, respectively. As shown in Fig 4a, the degradation of ROX was obviously enhanced by $\mathrm{O}_{2}$ purging, in which $57 \%$ of ROX was degraded after 40 hours of irradiation. For the assay with $\mathrm{N}_{2}$ purging, only $17 \%$ of ROX was degraded. Those results indicated that ROX photodegradation was mainly mediated by ROS. It is worth noticed that there was still $17 \%$ ROX being degraded with $\mathrm{N}_{2}$ purging, which might be caused by the residual DO (1.2 mg/L) or other mechanisms. In summary, it could be obtained that indirect photolysis by ROS was the main mechanism of ROX photodegradation.

For validating the role of ROS in the photodegradation, the degradation of ROX in $\mathrm{D}_{2} \mathrm{O}$ was further employed to verify the ${ }^{1} \mathrm{O}_{2}$ contribution by comparing it with the degradation of ROX in $\mathrm{H}_{2} \mathrm{O}$. As shown in Fig. 4b, the degradation efficiency of ROX in $\mathrm{D}_{2} \mathrm{O}$ was obviously higher than that in $\mathrm{H}_{2} \mathrm{O}$. This result indicated that the ROX photodegradation was mainly mediated by ${ }^{1} \mathrm{O}_{2}$, because ${ }^{1} \mathrm{O}_{2}$ in $\mathrm{D}_{2} \mathrm{O}$ has a long lifetime which can freely react with ROX. Because there were no other organic maters in the system except ROX, ROX might act as the photosensitizer to generate ${ }^{1} \mathrm{O}_{2}$. Those results and hypotheses were in accordance with the results of recent studies that ${ }^{1} \mathrm{O}_{2}$ can mediate self-sensitized photodegradation of organic pollutants in water, like p-arsanilic acid photodegradation (Xie et al., 2016; Xie et al., 2018).

\subsection{ROX photodegradation modeling and validation}

\subsubsection{ANN model building and training}

The ROX photodegradation model was built based on ANNs using the data of factors affecting ROX photodegradation. As shown in Fig. 5, eight parameters were considered as eight neurons in input layer (degradation time $(\mathrm{h}), \mathrm{ROX}$ concentration, light intensity $(\mu \mathrm{W} / \mathrm{cm} 2)$, temperature $\left({ }^{\circ} \mathrm{C}\right), \mathrm{DO}(\mathrm{mg} / \mathrm{L}), \mathrm{pH}^{\mathrm{N}} \mathrm{NO}_{3}{ }^{-}$ 
concentration $(\mathrm{mg} / \mathrm{L})$ and DOM concentration $(\mathrm{mg} / \mathrm{L}))$, 9-18 neurons in the hidden layer and one neuron (ROX degradation (\%)) in the output layer were used.

The data from the investigation of influencing factors were used for the training (Table S1). The training data were randomly divided into two groups ( $75 \%$ training ( 95 sets data) and $25 \%$ ( 32 sets data) as testing). Also, the inputs and outputs were normalized between -1 and 1 to avoid numerical overflows before training.

The number of neurons in the hidden layer is very important to optimize ANN topology. Many perceptrons with a different number of neurons in the hidden layer (9-18) were trained with 10 times by training data. Using the output of training data, the maximum and minimum values were removed and the mean squared error (MSE) was calculated. Based on these results (Fig. S2), the minimum of MSE (1.1885) was achieved with the inclusion of 13 neurons in the hidden layer. Therefore, the ANN model was built with 13 neurons in the hidden layer.

The ANN model was trained repeatedly as described above, the weights and bias data in Eq. 1 was listed in Tables 1-3, and the ANN model was saved for predicting ROX photodegradation.

\subsubsection{Validation of ANN model}

In order to validate the prediction accuracy of the built ANN model, the degradation of ROX in the water with different quality under sunlight irradiation was investigated. As shown in Fig.6, 62\% ROX was degraded in ultrapure water after 10 days. The degradation efficiency of ROX in surface water and wastewater was only $45 \%$ and $23 \%$ after 10 days, respectively. The lower degradation efficiency might be due to the DOM in wastewater, which inhibited the activity of ROS in the solution.

The data of experimental conditions for ROX photodegradation in different waters (Table S2) was used as the input in the built ANN model, and then got the predicted degradation rate. Fig. 6 showed the real experimental data and the ANN model prediction. It was found that the predicted degradation rate was in good agreement with the real values with a root mean square error of 1.008. The high precision indicated that the major factors affecting the degradation were considered in the built ANN model which can well predict ROX degradation.

\section{Conclusion}

In this study, the photodegradation behavior of ROX was investigated and modeled. ROX in the aquatic environment was oxidized to inorganic $A s(I I I)$ and $A s(V)$ under sunlight irradiation. The factors affecting ROX photodegradation were further investigated. The degradation efficiency gradually increased with the increase of light intensity mainly via indirect photolysis. The photodegradation was temperature dependence, but was only slightly affected by $\mathrm{pH} . \mathrm{NO}_{3}{ }^{-}$had an obvious influence, but sulfate, carbonate, and chlorate ions had a negligible effect on ROX degradation. ROX photodegrdation was mainly 
medicated by ROS (in form of ${ }^{1} \mathrm{O}_{2}$ ) which was generated through ROX self-sensitization under irradiation. The model of ROX photodegradation behavior was built based on ANNs and trained repeatedly using the data of factors affecting ROX photodegradation. The precision of the built ANN model was verified, and the predicted degradation rate was in good agreement with the real values with a root mean square error of 1.008. This study would expand our knowledge on the understanding of ROX photodegradation behavior and provide a basis for controlling the pollution caused from ROX photodegradation.

\section{Declarations}

Ethics approval and consent to participate: Not applicable.

Consent for publication: Not applicable.

Availability of data and materials: The datasets used and/or analysed during the current study are available from the corresponding author on reasonable request.

Competing interests: The authors declare that they have no competing interests

Funding: This research was supported by National Key R\&D Program of China (2019YFC0408502), the National Natural Science Foundation of China (51578205, 51538012, 51728801, and U19A20108), and China Scholarship Council (201906690044).

\section{Authors' contribution:}

Jizhong Meng carried out the experiment. All authors conceived and planned the experiments, discussed the results and commented on the manuscript, and helped shape the research, analysis and manuscript.

\section{References}

Amani-Ghadim AR, Dorraji MSS. Modeling of photocatalyatic process on synthesized ZnO nanoparticles: Kinetic model development and artificial neural networks. Applied Catalysis B-Environmental 2015; 163 : 539-546.

Bednar AJ, Garbarino JR, Ferrer I, Rutherford D, Wershaw R, Ranville J, et al. Photodegradation of roxarsone in poultry litter leachates. Science of the total environment 2003; 302: 237-245.

Cabaneros SM, Calautit JK, Hughes B. A review of artificial neural network models for ambient air pollution prediction. Environmental Modelling \& Software 2019; 119: 285-304.

Canonica S, Laubscher HU. Inhibitory effect of dissolved organic matter on triplet-induced oxidation of aquatic contaminants. Photochemical \& Photobiological Sciences 2008; 7: 547-551.

Chen N, Wang X, Wan Y, Luo Y, Huang Y, Zhang L. Simulated solar light driven Fe(III)/Fe(II) redox cycle for roxarsone degradation and simultaneous arsenate immobilization. Journal of Hazardous Materials 2020; 
Chen Y, Lin C, Zhou Y, Long L, Li L, Tang M, et al. Transformation of roxarsone during UV disinfection in the presence of ferric ions. Chemosphere 2019; 233: 431-439.

Cortinas I, Field JA, Kopplin M, Garbarino JR, Gandolfi AJ, Sierra-Alvarez R. Anaerobic Biotransformation of Roxarsone and Related N-Substituted Phenylarsonic Acids. Environmental Science \& Technology 2006; 40: 2951-2957.

Diepens M, Gijsman P. Influence of light intensity on the photodegradation of bisphenol A polycarbonate. Polymer Degradation and Stability 2009; 94: 34-38.

Elsheikh AH, Sharshir SW, Abd Elaziz M, Kabeel AE, Wang GL, Zhang HO. Modeling of solar energy systems using artificial neural network: A comprehensive review. Solar Energy 2019; 180: 622-639.

Fisher DJ, Yonkos LT, Staver KW. Environmental Concerns of Roxarsone in Broiler Poultry Feed and Litter in Maryland, USA. Environmental Science \& Technology 2015; 49: 1999-2012.

Hansen AM, Kraus TEC, Pellerin BA, Fleck JA, Downing BD, Bergamaschi BA. Optical properties of dissolved organic matter (DOM): Effects of biological and photolytic degradation. Limnology and Oceanography 2016; 61: 1015-1032.

Huang W, Wang X, Zhang W, Zhang S, Tian Y, Chen Z, et al. Intraligand charge transfer boosts visiblelight-driven generation of singlet oxygen by metal-organic frameworks. Applied Catalysis B:

Environmental 2020; 273.

Janssen EM-L, Erickson PR, McNeill K. Dual roles of dissolved organic matter as sensitizer and quencher in the photooxidation of tryptophan. Environmental science \& technology 2014; 48: 4916-4924.

Latch DE, Stender BL, Packer JL, Arnold WA, McNeill K. Photochemical fate of pharmaceuticals in the environment: Cimetidine and ranitidine. Environmental Science \& Technology 2003; 37: 3342-3350.

Lei M, Dong ZP, Jiang Y, Longhurst P, Wan XM, Zhou GD. Reaction mechanism of arsenic capture by a calcium-based sorbent during the combustion of arsenic-contaminated biomass: A pilot-scale experience. Frontiers Of Environmental Science \& Engineering 2019; 13: 24-33.

Liu XP, Zhang WF, Hu YN, Hu ED, Xie XD, Wang LL, et al. Arsenic pollution of agricultural soils by concentrated China animal feeding operations (CAFOs). Chemosphere 2015; 119: 273-281.

Mangalgiri KP, Adak A, Blaney L. Organoarsenicals in poultry litter: Detection, fate, and toxicity. Environment International 2015; 75: 68-80.

Meng JZ, Xu F, Yuan SJ, Mu Y, Wang W, Hu ZH. Photocatalytic oxidation of roxarsone using riboflavinderivative as a photosensitizer. Chemical Engineering Journal 2019; 355: 130-136. 
Nguyen CC, Hugie CN, Kile ML, Navab-Daneshmand T. Association between heavy metals and antibioticresistant human pathogens in environmental reservoirs: A review. Frontiers Of Environmental Science \& Engineering 2019; 13: 46-63.

Niu JF, Li Y, Wang WL. Light-source-dependent role of nitrate and humic acid in tetracycline photolysis: Kinetics and mechanism. Chemosphere 2013; 92: 1423-1429.

Qin-Tao L, Williams HE. Kinetics and degradation products for direct photolysis of $\beta$-blockers in water. Environmental science \& technology 2007; 41: 803-810.

Rutherford DW, Bednar AJ, Garbarino JR, Needham R, Staver KW, Wershaw RL. Environmental fate of roxarsone in poultry litter. part II. Mobility of arsenic in soils amended with poultry litter. Environmental Science \& Technology 2003; 37: 1515-1520.

Sharpless CM. Lifetimes of Triplet Dissolved Natural Organic Matter (DOM) and the Effect of NaBH4 Reduction on Singlet Oxygen Quantum Yields: Implications for DOM Photophysics. Environmental Science \& Technology 2012; 46: 4466-4473.

Shui M, Ji F, Tang R, Yuan S, Zhan X, Wang W, et al. Impact of roxarsone on the UASB reactor performance and its degradation. Frontiers of Environmental Science \& Engineering 2016; 10: 4.

Su S, Cao C, Zhao Y, Dionysiou DD. Efficient transformation and elimination of roxarsone and its metabolites by a new a-FeOOH@GCA activating persulfate system under UV irradiation with subsequent As(V) recovery. Applied Catalysis B-Environmental 2019; 245: 207-219.

Tang R, Chen H, Yuan SJ, Zhan XM, Wang W, Hu ZH. Arsenic accumulation and volatilization in a 260-day cultured upflow anaerobic sludge blanket (UASB) reactor. Chemical Engineering Journal 2017; 311: 277283.

Tang R, Wu G, Yue Z, Wang W, Zhan XM, Hu ZH. Anaerobic biotransformation of roxarsone regulated by sulfate: Degradation, arsenic accumulation and volatilization. Environmental Pollution 2020; 267: 115602.

Tang R, Yuan SJ, Chen FQ, Zhan XM, Wang W, Hu ZH. Effects of roxarsone and sulfadiazine on biogas production and their degradation during anaerobic digestion. International Biodeterioration \& Biodegradation 2019; 140: 113-118.

Uwayezu JN, Yeung LWY, Backstrom M. Sorption of PFOS isomers on goethite as a function of $\mathrm{pH}$, dissolved organic matter (humic and fulvic acid) and sulfate. Chemosphere 2019; 233: 896-904.

Wang X, Chen Y, Li T, Liang J, Zhou L. High-efficient elimination of roxarsone by MoS2@Schwertmannite via heterogeneous photo-Fenton oxidation and simultaneous arsenic immobilization. Chemical Engineering Journal 2021; 405: 126952. 
Wang YF, Roddick FA, Fan LH. Direct and indirect photolysis of seven micropollutants in secondary effluent from a wastewater lagoon. Chemosphere 2017; 185: 297-308.

Wenk J, Eustis SN, McNeill K, Canonica S. Quenching of Excited Triplet States by Dissolved Natural Organic Matter. Environmental Science \& Technology 2013; 47: 12802-12810.

Xie XD, Hu YN, Cheng HF. Mechanism, kinetics, and pathways of self-sensitized sunlight photodegradation of phenylarsonic compounds. Water Research 2016; 96: 136-147.

Xie XD, Zhang ZC, Hu YN, Cheng HF. A mechanistic kinetic model for singlet oxygen mediated selfsensitized photo-oxidation of organic pollutants in water. Chemical Engineering Journal 2018; 334: 12421251.

Xu B, Chen Z, Qi F, Shen J, Wu F. Factors influencing the photodegradation of N-nitrosodimethylamine in drinking water. Front. Environ. Sci. Eng. 2009; 3: 91-97.

Xu ZH, Jing CY, Li FS, Meng XG. Mechanisms of photocatalytical degradation of monomethylarsonic and dimethylarsinic acids using nanocrystalline titanium dioxide. Environmental Science \& Technology 2008; 42: 2349-2354.

Yang ZL, Peng HY, Lu XF, Liu QQ, Huang RF, Hu B, et al. Arsenic Metabolites, Including N-Acetyl-4-hydroxym-arsanilic Acid, in Chicken Litter from a Roxarsone-Feeding Study Involving 1600 Chickens. Environmental Science \& Technology 2016; 50: 6737-6743.

Ye J, Cong XN, Zhang PY, Zeng GM, Hoffmann E, Wu Y, et al. Operational parameter impact and back propagation artificial neural network modeling for phosphate adsorption onto acid-activated neutralized red mud. Journal of Molecular Liquids 2016; 216: 35-41.

Zhang FF, Wang W, Yuan SJ, Hu ZH. Biodegradation and speciation of roxarsone in an anaerobic granular sludge system and its impacts. Journal of Hazardous Materials 2014; 279: 562-568.

Zhao D, Wang J, Yin D, Li M, Chen X, Juhasz AL, et al. Arsanilic acid contributes more to total arsenic than roxarsone in chicken meat from Chinese markets. Journal of Hazardous Materials 2020; 383: 121178121187.

Zheng S, Jiang W, Cai Y, Dionysiou DD, O'Shea KE. Adsorption and photocatalytic degradation of aromatic organoarsenic compounds in TiO2 suspension. Catalysis Today 2014; 224: 83-88.

\section{Figures}




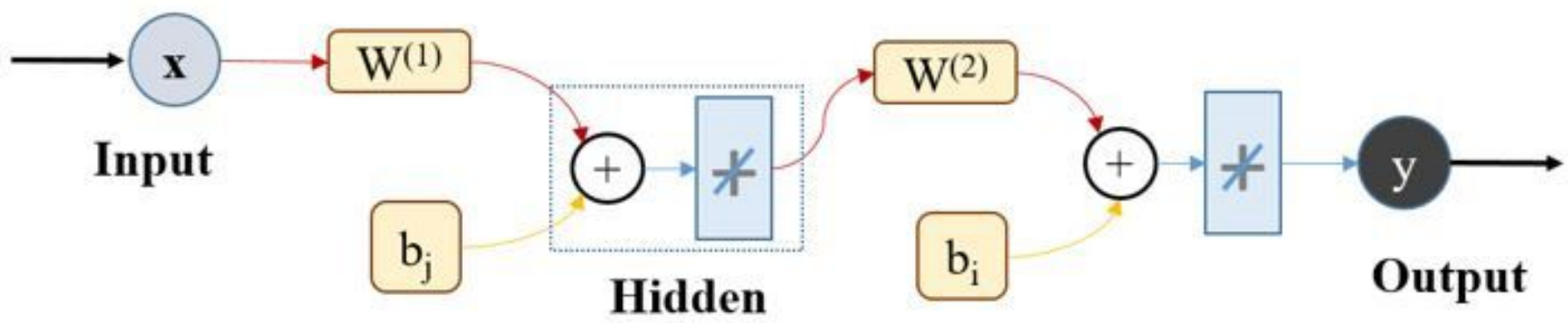

Figure 1

Schematic diagram of the backpropagation algorithm with forward pass procedure

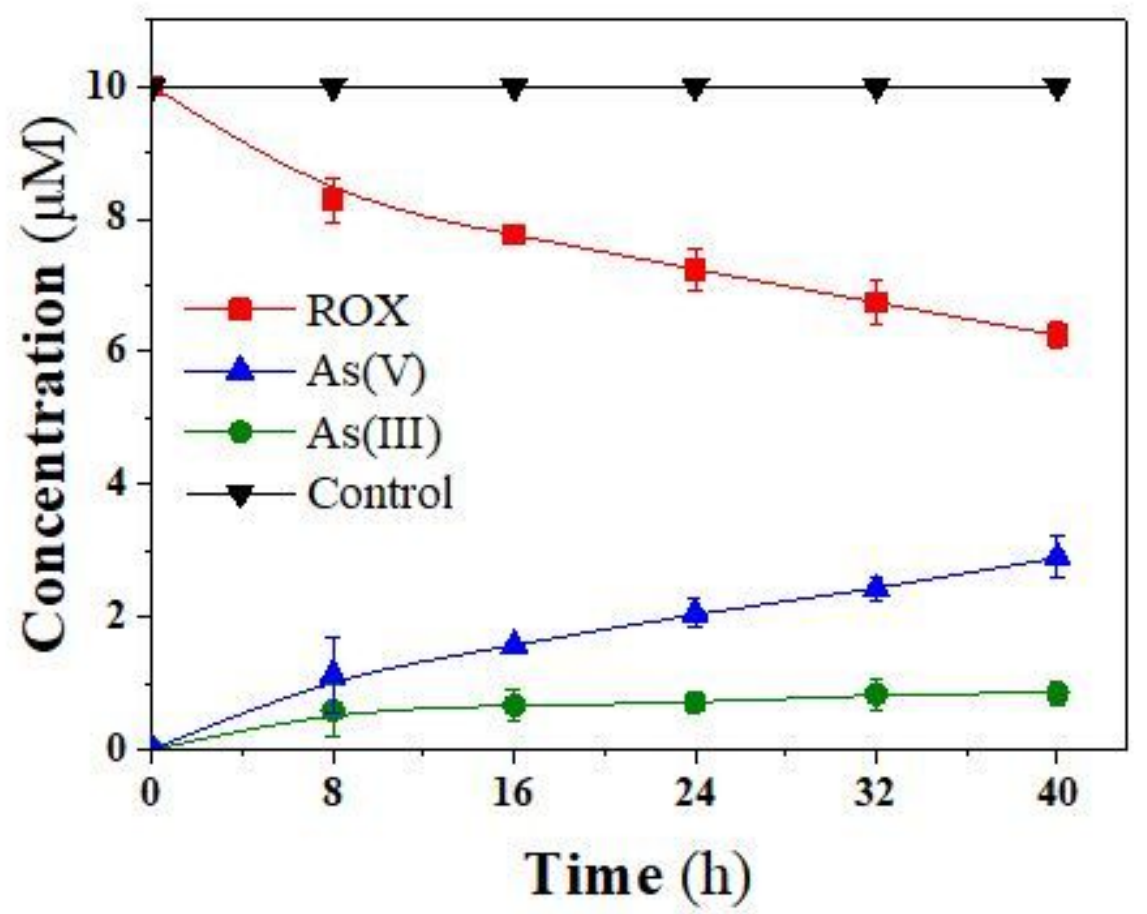

Figure 2

Photodegradation of ROX and generation of inorganic arsenic species in ultrapure water. ROX decomposition in darkness was set as control. Experimental conditions: [ROX]0 $10.0 \mu \mathrm{M}, \mathrm{pH} 7.0 \pm 0.2$, light intensity $800 \pm 30 \mu \mathrm{W} / \mathrm{cm} 2$ at $254 \mathrm{~nm}$, and temperature $25.0 \mathrm{oC}$ 

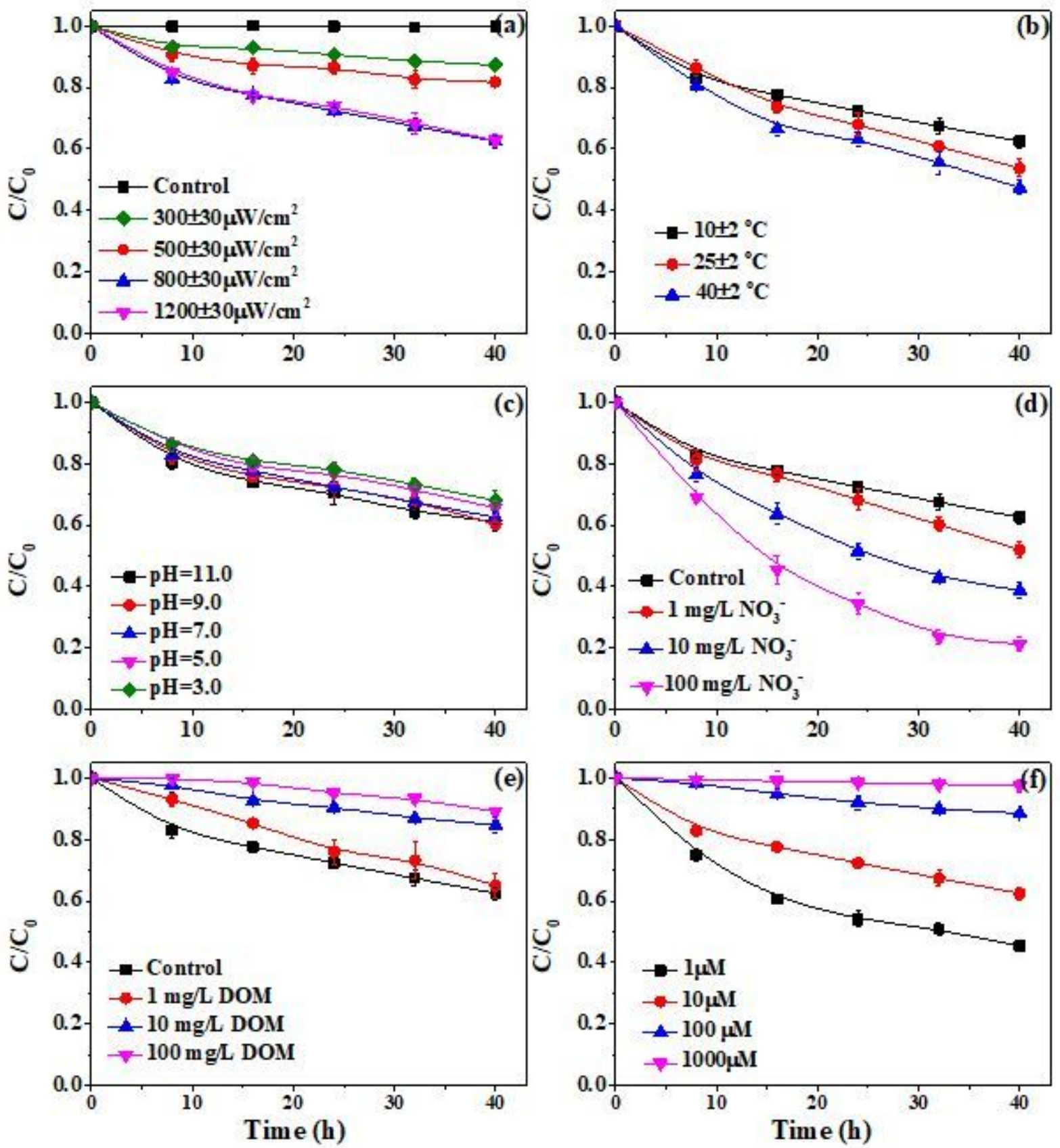

Figure 3

The factors affecting ROX photodegradation, (a) light intensity, (b) temperature, (c) pH, (d) NO3concentration, (e) DOM concentration, and (f) ROX concentration. Experimental conditions: (a): [ROX]0 $10.0 \mu \mathrm{M}, \mathrm{pH} 7.0 \pm 0.2$, and temperature $25.0 \mathrm{oC}$, (b): [ROX]0 $10.0 \mu \mathrm{M}$, light intensity $800 \pm 30 \mu \mathrm{W} / \mathrm{cm} 2$, and pH $7.0 \pm 0.2$, (c): [ROX]0 $10.0 \mu \mathrm{M}$, light intensity $800 \pm 30 \mu \mathrm{W} / \mathrm{cm} 2$ and temperature $25.0 \mathrm{oC}$, (d) and (e): [ROX]0 $10.0 \mu \mathrm{M}$, light intensity $800 \pm 30 \mu \mathrm{W} / \mathrm{cm} 2, \mathrm{pH} 7.0 \pm 0.2$, and temperature $25.0 \mathrm{oC}$, (f) light intensity $800 \pm 30 \mu \mathrm{W} / \mathrm{cm} 2, \mathrm{pH} 7.0 \pm 0.2$, and temperature $25.0 \mathrm{oC}$ 

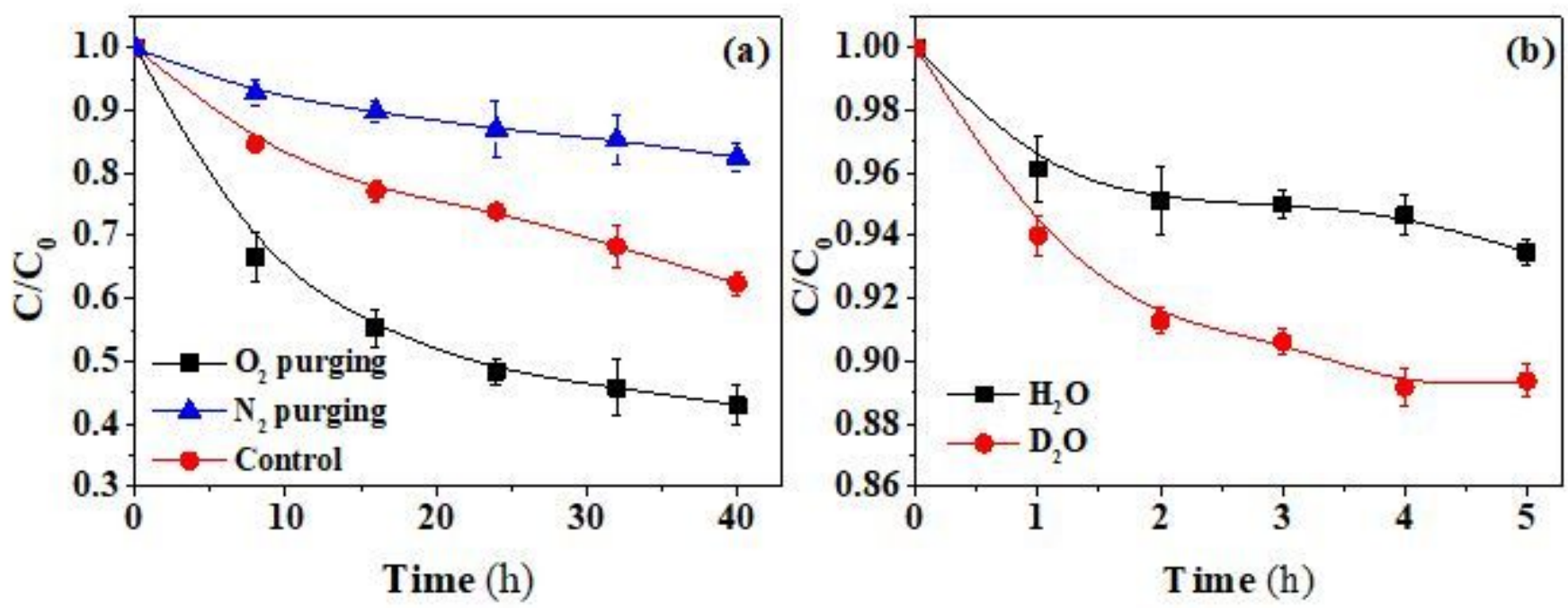

Figure 4

Photodegradation of ROX under simulated sunlight irradiation with 02 and N2 purging in ultrapure water (a), and comparison of photodegradation of ROX in ultrapure water and D2O (b). Experimental conditions: [ROX]0 $10.0 \mu \mathrm{M}, \mathrm{pH} 7.0 \pm 0.2$, light intensity $800 \pm 30 \mu \mathrm{W} / \mathrm{cm} 2$, and temperature $25.0 \mathrm{oC}$.

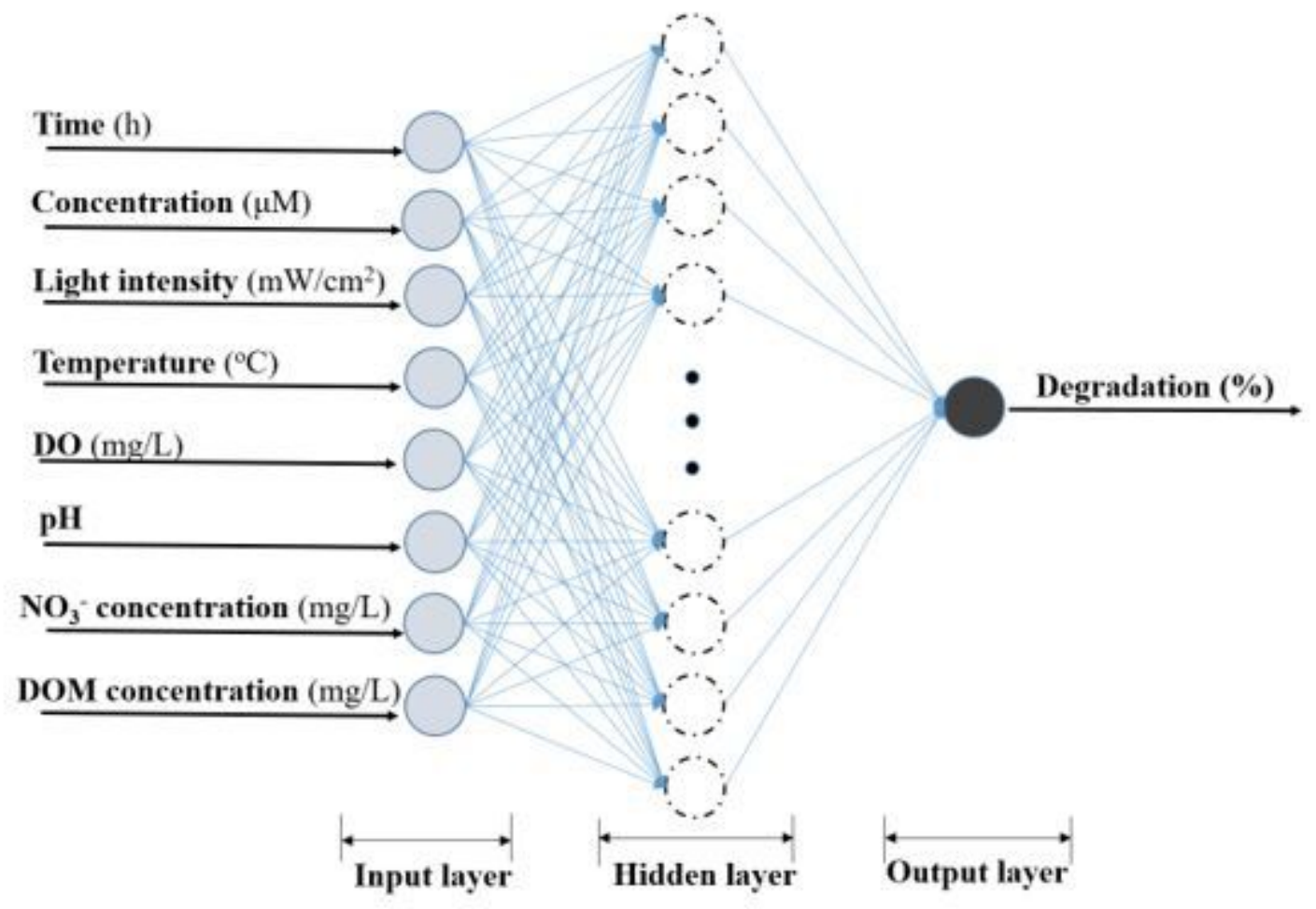

Figure 5 


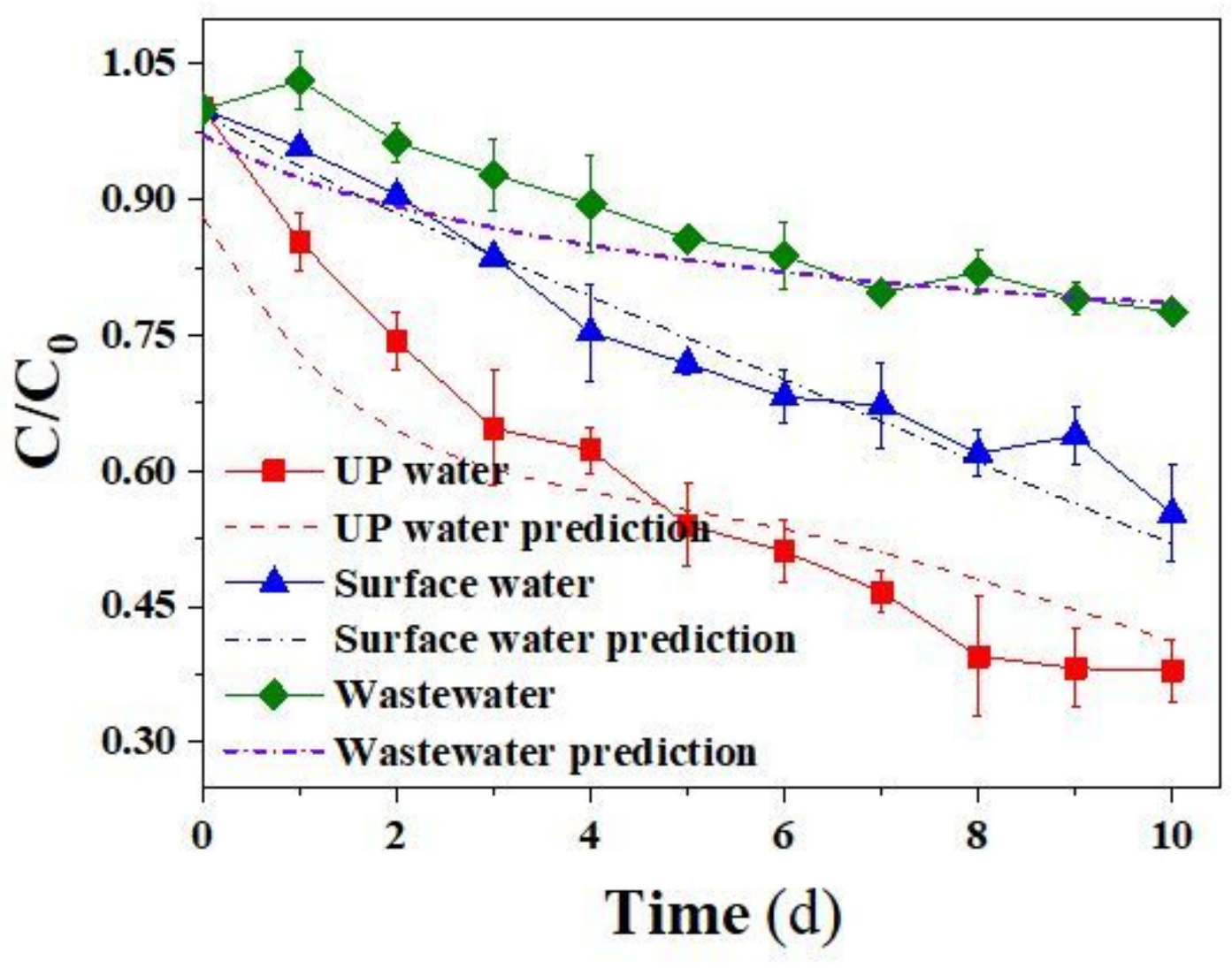

Figure 6

ROX photodegradation in different water under sunlight irradiation and the prediction using the ANN model. Experimental conditions: [ROX]0 $10.0 \mu \mathrm{M}, \mathrm{pH} 6.5 \pm 0.2$, average temperature $35 \mathrm{oC}$, average light intensity $1200 \mu \mathrm{W} / \mathrm{cm} 2$

\section{Supplementary Files}

This is a list of supplementary files associated with this preprint. Click to download.

- equations.docx

- Supportinformation20210418.docx 